\title{
The biosynthesis of $\mathrm{N}$-arachidonoyl dopamine (NADA), a putative endocannabinoid and endovanilloid, via conjugation of arachidonic acid with dopamine
}

\author{
Sherry Shu-Jung Hu${ }^{1}$, Heather B. Bradshaw ${ }^{1,2, \ddagger}$, Valery M. Benton ${ }^{1}$, Jay Shih-Chieh \\ Chen ${ }^{1}$, Susan M. Huang ${ }^{3}$, Alberto Minassi ${ }^{4, \#}$, Tiziana Bisogno ${ }^{4}$, Kim Masuda $^{5}$, Bo Tan ${ }^{1}$, \\ Robert Roskoski Jr. ${ }^{6}$, Benjamin F. Cravatt ${ }^{5}$, Vincenzo Di Marzo ${ }^{4}$, and J. Michael Walker ${ }^{\prime}$ \\ ${ }^{1}$ Department of Psychological and Brain Sciences and the Gill Center for Biomolecular Science, \\ Indiana University, Bloomington, IN 47405 USA \\ ${ }^{2}$ The Kinsey Institute for Research in Sex, Gender and Reproduction, Indiana University, \\ Bloomington, IN 47405 USA \\ ${ }^{3}$ Department of Biological Chemistry, Johns Hopkins University, Baltimore, MD 21205 USA \\ ${ }^{4}$ Endocannabinoid Research Group, Institute of Biomolecular Chemistry, National Research \\ Council, Pozzuoli, Napoli, Italy. \\ ${ }^{5}$ Departments of Cell Biology and Chemistry, the Scripps Research Institute, La Jolla, CA 92037 \\ USA \\ ${ }^{6}$ Department of Biochemistry and Molecular Biology, Louisiana State University Medical Center, \\ New Orleans, LA 70119 USA.
}

\section{Summary}

$\mathrm{N}$-arachidonoyl dopamine (NADA) is an endogenous ligand that activates the cannabinoid type 1 receptor and the transient receptor potential vanilloid type 1 channel. Two potential biosynthetic pathways for NADA have been proposed, though no conclusive evidence exists for either. The first is the direct conjugation of arachidonic acid with dopamine; the other is via metabolism of a putative $\mathrm{N}$-arachidonoyl tyrosine (NA-tyrosine). In the present study we investigated these biosynthetic mechanisms and report that NADA synthesis requires TH in dopaminergic terminals, however, NAtyrosine, which we identify here as an endogenous lipid, is not an intermediate. We show that NADA biosynthesis primarily occurs through an enzyme-mediated conjugation of arachidonic acid with dopamine. While this conjugation likely involves a complex of enzymes, our data suggest a direct involvement of fatty acid amide hydrolase in NADA biosynthesis as either a rate-limiting enzyme that liberates arachidonic acid from AEA, as a conjugation enzyme, or both.

\section{Keywords}

NADA; dopamine; TH; FAAH; biosynthesis

\$Correspondence: Dr. Heather B. Bradshaw, Department of Psychological and Brain Sciences, the Kinsey Institute of Research in Sex, Gender, and Reproduction, Indiana University, 1101 E. 10th Street, Bloomington, IN 47405, USA. Tel. 812 856-1559; Fax. 812 855-4691; hbbradsh@indiana.edu.

\#Current address: 3DISCAFF, Università del Piemonte Orientale, Novara, Italy

Publisher's Disclaimer: This is a PDF file of an unedited manuscript that has been accepted for publication. As a service to our customers we are providing this early version of the manuscript. The manuscript will undergo copyediting, typesetting, and review of the resulting proof before it is published in its final citable form. Please note that during the production process errors may be discovered which could affect the content, and all legal disclaimers that apply to the journal pertain. 


\section{Introduction}

$\mathrm{N}$-Arachidonoyl dopamine (NADA) was recently identified as an endogenous capsaicin-like compound that displays nanomolar potency for cannabinoid type 1 receptors $\left(\mathrm{CB}_{1}\right)$ and transient receptor potential vanilloid type 1 (TRPV1) channels. It is found in brain areas with a high density of TRPV1 (i.e., the striatum, hippocampus, cerebellum, and dorsal root ganglia (DRG)) [1-3], suggesting it may be an endogenous ligand for this channel.

In DRG neurons, NADA increased intracellular $\mathrm{Ca}^{2+}$ through activation of $\mathrm{CB}_{1}$ receptors and depolarized membrane potential via TRPV1 channels [1,4]. NADA also increased TRPV1mediated release of substance $P$ and calcitonin gene-related peptide (CGRP) in rat dorsal spinal cord slices [1]. Furthermore, NADA enhanced TRPV1-mediated paired-pulse depression by increasing GABAergic transmission in rat hippocampal slices [1]. NADA also initiated vasorelaxant effects via the activation of TRPV1 and $\mathrm{CB}_{1}$ receptors in small mesenteric vessels [5]. Finally, NADA leads to a $\mathrm{CB}_{1}$-mediated reduction of GABAergic and glutamatergic transmission, and to TRPV1-mediated stimulation of glutamatergic transmission, onto dopaminergic neurons in rat substantia nigra slices [6].

In addition to the in vitro effects described above, NADA exerts opposing effects on pain modulation via the activation of $\mathrm{CB}_{1}$ and TRPV1, respectively. In contrast to $\mathrm{CB}_{1}$-mediated analgesia observed when administrated intraperitoneally (i.p.) in mice $(10 \mathrm{mg} / \mathrm{kg})$, NADA induced TRPV1-mediated thermal hyperalgesia $\left(\mathrm{EC}_{50}=1.5 \mu \mathrm{g} / 50 \mu \mathrm{l}=68.2 \mu \mathrm{M}\right)$ when injected intradermally (i.pl.) into the rat hindpaw [1,3]. Correspondingly, Huang and Walker [7] identified the neural correlates of behavioral thermal hyperalgesia in anesthetized rats. They found that when administrated intradermally (i.pl.) into the receptive fields of dorsal horn nociceptive neurons of the ipsilateral hindpaw, NADA increased both spontaneous and heatevoked activity in spinal nociceptive neurons. NADA-induced neural hypersensitivity was dose-dependent $\left(\mathrm{EC}_{50}=1.55 \mu \mathrm{g} / 50 \mu \mathrm{l}=68.2 \mu \mathrm{M}\right)$ and TRPV1-dependent, but $\mathrm{CB}_{1^{-}}$ independent. However, other researchers found that NADA inhibited both $\mathrm{CB}_{1}$-mediated innocuous mechanically evoked responses of dorsal horn neurons, and TRPV1-mediated noxious-evoked responses of dorsal horn neurons, when injected intradermally (i.pl.) into the receptive fields of neurons [4]. These findings suggest complex effects of NADA on sensory neurons, presumably due to the differential expression of $\mathrm{CB}_{1}$ receptors and TRPV1 channels on the primary afferent fibers and/or different molecular mechanisms for different stimulus modalities [4].

As a putative endocannabinoid and endovanilloid, NADA may play a role in pain and inflammation through the activation of $\mathrm{CB}_{1}$ and TRPV1. Therefore, it is important to elucidate the pathways of its biosynthesis. There are several potential routes for NADA biosynthesis, based on previous knowledge of the formation of dopamine or of the occurrence of phospholipid aminolysis. One possibility is that NADA may be synthesized from a putative NA-tyrosine that could be converted to NA-L-DOPA and NADA by the same enzymes that convert tyrosine to dopamine; another possible mechanism is through conjugation of arachidonic acid with dopamine (see Fig. 1). Huang and colleagues [1] observed that a compound with chromatographic properties identical to NADA could be biosynthesized in rat brain homogenates incubated with radiolabeled arachidonic acid and dopamine or tyrosine. In addition, the enzymatic formation of the radiolabeled NADA-like compound from tyrosine was reduced by inhibition of $\mathrm{TH}$, which is evidence in support of both this and the aforementioned route [1]. In either of the above cases, the conjugation of dopamine or tyrosine and arachidonic acid might occur via direct condensation or via the previous formation of arachidonoyl-CoA, which would be more reactive to the nucleophilic attack by the $\mathrm{NH}_{2}$ group of the two amines. Finally, NADA might be formed in principle also via the dopamine-induced 
aminolysis of the arachidonoyl-glycerol ester bond in phospholipids [8], or else its synthesis might use as biosynthetic precursor a preferential pool of arachidonic acid esterified in phospholipids rather than free or CoA-activated arachidonic acid. NADA is rapidly taken up by a putative endocannabinoid transporter in C6 glioma cells and is hydrolyzed (albeit significantly more slowly than AEA) by fatty acid amide hydrolase (FAAH) to arachidonic acid and dopamine [1]. Conversely, NADA was shown to be a good substrate for $O$ catecholamine-methyl-transferase in this experiment [1]. To date it is not known if manipulation of FAAH activity affects NADA levels. Recently FAAH was reported to participate in the synthesis of $N$-arachidonoyl phenolamine (AM404) by conjugation of arachidonic acid to exogenously administered acetaminophen [9] and, therefore, a potential participant in an arachidonic acid and dopamine conjugation pathway.

The aim of this study was to examine these proposed biosynthetic pathways for NADA using both in vivo and in vitro assays and to investigate the involvement of several enzymes, including FAAH in regulating NADA production. We demonstrate that NA-tyrosine is formed endogenously in rat brain; however, it does not appear to be a precursor for NADA in the striatum. Additionally, in vitro experiments suggest that arachiodonoyl CoA and arachidonic acid esterified to phospholipids are not direct precursors to NADA. However, we do show through both in vitro and in vivo assays that the primary biosynthetic pathway is via conjugation of arachidonic acid to dopamine through a FAAH-dependent pathway. FAAH is likely acting as part of a complex of mitochondrial enzymes that are involved in the biosynthesis and metabolism of the larger family of $N$-acyl amides.

\section{Materials and Methods}

\subsection{Animals}

Male Sprague-Dawley rats (Charles River, Boston, MA) weighing between 300-400 g served as experimental subjects. All animals were housed in groups prior to surgery, and singly thereafter, under controlled lighting conditions (lights on from 7 AM to 7 PM) and at room temperature. Food and water were available ad libitum. Additionally, 10 mice were used. Five wild type and five FAAH knockout mice used in this study were littermates from the thirteenth generation offspring from intercrosses of $129 \mathrm{SvJ}-\mathrm{C} 57 \mathrm{BL} / 6 \mathrm{FAAH}( \pm)$ mice [10]. All protocols were approved by the Brown University, Indiana University, and Scripps Research Institutional Animal Care and Use Committee.

\subsection{Chemicals}

All chemicals were obtained from Sigma-Aldrich (St. Louis, MO) unless otherwise stated. $\left[{ }^{2} \mathrm{H}_{4}\right]$ dopamine was obtained from Cambridge Isotope Laboratories (Andover, MA). Dithiothreitol (DTT) was obtained from Promega (Madison, WI). URB597 was obtained from BioMol International (Plymouth Meeting, PA). $\left[2,5,6-{ }^{3} \mathrm{H}\right]$ dopamine was obtained from Amersham Biosciences (Pittsburgh, PA). $\left[1-{ }^{13} \mathrm{C}\right]$ Arachidonoyl-CoA was obtained from American Radiolabeled Chemicals, Inc. (St. Louis, MO). TH was purified from rat PC12 cells as described [11]. Tetrahydrobiopterin $\left(\mathrm{BH}_{4}\right)$ was provided by Dr. Robert Roskoski, Jr.. NAtyrosine, $\left[{ }^{2} \mathrm{H}_{8}\right] \mathrm{NA}$-tyrosine, $\left[{ }^{2} \mathrm{H}_{8}\right] \mathrm{NA}-\mathrm{L}-\mathrm{DOPA},\left[{ }^{2} \mathrm{H}_{8}\right] \mathrm{NADA}$ were synthesized from the corresponding amines and arachidonoylchloride or $\left[{ }^{2} \mathrm{H}_{8}\right]$ arachidonoylchloride as described $[2,3,12]$.

\subsection{Partial purification of dopamine and NADA in rat brain}

Striata were homogenized in $2 \mathrm{ml}$ of ice-cold methanol by sonication with a Brinkmann sonicator (Kinematica $\mathrm{GmbH}$, Switzerland) for $1 \mathrm{~min}$ and centrifuged at $31,000 \times \mathrm{g}$ at $4{ }^{\circ} \mathrm{C}$ for $20 \mathrm{~min}$. Supernatants were removed and $2 \mathrm{ml}$ of $1 \mathrm{M}$ Tris buffer solution containing $0.1 \%$ glutathione and $0.1 \%$ semicarbazide hydrochloride (adjusted to $\mathrm{pH} 8.5$ with $1 \mathrm{M} \mathrm{HCl}$ ) was 
added to methanol extract. Silica-based $500 \mathrm{mg}$ phenylboronic acid solid phase cartridges (PBA, Varian, Harbor City, CA) were conditioned with $1 \mathrm{ml}$ methanol, $1 \mathrm{ml}$ water, and $1 \mathrm{ml}$ saturated $\mathrm{NaHCO}_{3}$ buffer solution (pH 9). The extract was loaded on PBA cartridges and passed through by gentle low-pressure aspiration. After washing with $1 \mathrm{ml}$ water and $2 \mathrm{ml}$ methanol, dopamine was eluted from cartridges with $0.5,1$, and $1 \mathrm{ml}$ of $5 \mathrm{M}$ formic acid/methanol (1:5, $\mathrm{v} / \mathrm{v}) .1 \mu \mathrm{l}$ of each elution was then used for LC/MS/MS analysis. Dopamine was chromatographed by an isocratic method with a mobile phase containing $5 \%$ methanol, $0.05 \%$ acetic acid, and $1 \mathrm{mM}$ ammonium acetate. After the LC/MS/MS analysis for dopamine, 2.7 $\mathrm{ml}$ water was added to the original $2.5 \mathrm{ml}$ eluent. C18-SD $(4 \mathrm{~mm} / 1 \mathrm{ml})$ high performance extraction disk cartridges (3M Bioanalytical Technologies, St. Paul, MN) were conditioned with $150 \mu \mathrm{l}$ methanol and $300 \mu \mathrm{l}$ water. The samples were loaded on the disk cartridges $(1 \mathrm{ml})$ and washed with $300 \mu 15 \%$ methanol. NADA was eluted with $100 \mu 1$ methanol and $10 \mu \mathrm{l}$ of each elution was used for LC/MS/MS analysis. NADA was chromatographed by gradient elution: Mobile phase A: $20 \%$ methanol, $0.5 \%$ acetic acid, $1 \mathrm{mM}$ ammonium acetate; mobile phase B: $100 \%$ methanol, $0.5 \%$ acetic acid, $1 \mathrm{mM}$ ammonium acetate; $25 \%$ B to $100 \%$ B 5.50 min, followed by 1 min re-equilibration with $25 \% \mathrm{~B}$.

Analysis of all extracts was performed with an Applied Biosystems/MDS Sciex (Foster City, CA) API 3000 triple quadrupole mass spectrometer (LC/MS/MS). Dopamine samples were injected onto a 100-mm Aquasil C18 reversed phase HPLC column (2.1-mm internal diameter, $0.200 \mathrm{ml} / \mathrm{min}$ ) (Thermo Electron Corporation, San Jose, CA) and NADA samples were injected onto a 50-mm Zorbax Eclipse XDB-C18 reversed phase HPLC column (2.1-mm internal diameter, $0.200 \mathrm{ml} / \mathrm{min}$ ) (Agilent Technologies Inc., New Castle, DE). Levels were analyzed in multiple reaction monitoring mode (MRM) on the LC/MS/MS system. In MRM mode, detection is based on the fragmentation of the precursor ion $\left(\mathrm{MH}^{+}\right.$or $\left.\mathrm{MH}^{-}\right)$to yield a prominent product ion. For dopamine, $\mathrm{MH}^{+}=m / z$ 154.1, product ions $=m / z$ 91.2, 119.0, and 65.1. For NADA, $\mathrm{MH}^{-}=m / z 438.4$, product ion $=m / z$ 123.1.

\subsection{Partial purification of NA-tyrosine in rat brain}

Using six fresh male rat brains lipid extractions were performed as previously described [1, 10]. Levels of NA-tyrosine were analyzed in MRM mode on the LC/MS/MS system with a method optimized with the synthetic standard that generated a parent ion of NA-tyrosine, $\mathrm{MH}^{-}=m / z 466.3$ and product ions $=m / z, 118.9,162.9$, and 179.9. The gradient used to elute NA-tyrosine was the same as that used for NADA. NA-tyrosine standards were added to separate brain extracts to obtain percentage recoveries.

\subsection{Nano-HPLC quadrupole TOF analysis for NA-tyrosine}

Exact mass measurements and structural characteristics of NA-tyrosine from rat brain extracts was made with a quadrupole time-of-flight (qTOF) LC/MS/MS mass spectrometer as previously described [13]. One difference in the methodologies was that the ESI voltage was - 3000V to generate a negatively charged NA-tyrosine molecular ion, whereas the previous report identified $N$-palmitoyl glycine with a positive voltage.

\subsection{Quantification of L-DOPA and NA-L-DOPA}

Quantitative analysis of all extracts was performed with a Shimadzu gradient HPLC system and an Applied Biosystems/MDS Sciex API 3000 triple quadrupole mass spectrometer (LC/ MS/MS) (Foster City, CA). L-DOPA samples were injected onto an Aquasil C18 reversed phase HPLC column $(100 \mathrm{~mm} \times 2.1 \mathrm{~mm}$ i.d., $0.200 \mathrm{ml} / \mathrm{min}$, Thermo Electron Corporation, San Jose, CA) and NA-L-DOPA samples were injected onto a $50 \mathrm{~mm}$ Zorbax Eclipse XDBC18 reversed phase HPLC column $(2.1 \mathrm{~mm}$ i.d., $0.200 \mathrm{ml} / \mathrm{min}$ ) (Agilent Technologies Inc., New Castle, DE). Levels were determined in MRM mode on the LC/MS/MS system. For LDOPA, $\mathrm{MH}^{-}=m / z$ 195.9, product ions $=m / z$ 135.1, 121.9, and 108.9. For NA-L-DOPA, 
$\mathrm{MH}^{-}=m / z$ 482.4, product ion $=m / z$ 195.9. The mobile phase used to elute L-DOPA was the same as that used for dopamine, and the gradient used to elute NA-L-DOPA was the same as that used for NADA. Percentage recoveries for L-DOPA and NA-L-DOPA samples were determined by separate assay solutions processed in the presence of L-DOPA and NA-L-DOPA standards.

\subsection{6-Hydroxydopamine (6-OHDA) lesions}

Rats $(n=5)$ were initially injected with desipramine $(15 \mathrm{mg} / \mathrm{kg}$, i.p.) to protect noradrenergic terminals. Under deep nembutal anesthesia $(45 \mathrm{mg} / \mathrm{kg}$, i.p.) rats received a unilateral 6-OHDA lesion (total $8 \mu \mathrm{g}$ in $4 \mu \mathrm{l}$ of $0.008 \%$ ascorbic acid kept on ice) to the left medial forebrain bundle over an 8-min period (coordinates from bregma: anteroposterior, $-3.0 \mathrm{~mm}$; mediolateral, -1.4 $\mathrm{mm}$; dorsoventral, $-9.5 \mathrm{~mm}$ from skull). The syringe was left in place for $1 \mathrm{~min}$ before removal. Seven days after surgery, both left (lesioned side) and right (control side) striata were removed from 6-OHDA lesioned animals and were processed for LC/MS/MS analysis as described above for analysis of dopamine and NADA.

\subsection{TH inhibition}

Rats ( $\mathrm{n}=4$ at each time point) were injected intraperitoneally (i.p.) the TH inhibitor, DL- $\alpha$ methyltyrosine methyl ester $\mathrm{HCl}$ (AMPT) $(115 \mathrm{mg} / \mathrm{kg}$ ) [14] and sacrificed at 90, 180, 270, 360 , and $450 \mathrm{~min}$. Both the ipsilateral and contralateral striata were quickly dissected and frozen on dry ice (stored thereafter at $-80{ }^{\circ} \mathrm{C}$ for no more than 2 weeks). Control animals were sacrificed immediately (time $=0$ ) after injection of distilled water (vehicle). The striata were processed as described above for analysis of dopamine and NADA. In addition, rat brains (n $=8$ ) obtained at $270 \mathrm{~min}$ after AMPT injection were processed according to the NA-tyrosine extraction procedure for LC/MS/MS analysis.

\subsection{Synthesis of L-DOPA or NA-L-DOPA in cell-free TH assays}

L-tyrosine $(1 \mu \mathrm{M})$ or $\left[{ }^{2} \mathrm{H}_{8}\right] \mathrm{NA}$-tyrosine $(1 \mu \mathrm{M})$ was incubated separately with $16.5 \mu \mathrm{g} \mathrm{TH}$ at $37^{\circ} \mathrm{C}$ for $10 \mathrm{~min}$ in $100 \mu \mathrm{l}$ of $50 \mathrm{mM}$ PIPES, pH 6.0, which also includes $1 \mathrm{mM} \mathrm{BH}_{4}, 50 \mu \mathrm{g} /$ $\mathrm{ml}$ catalase, and $5 \mathrm{mM}$ DTT. The reaction was terminated with $300 \mu \mathrm{l} 100 \%$ methanol (final volume $400 \mu \mathrm{l}$ ). Buffer or boiled enzyme conditions were also tested. After termination of the reaction, the NA-L-DOPA assay solution $(400 \mu \mathrm{l})$ was used for LC/MS/MS analysis as described above. The L-DOPA assay solution was evaporated in a SpeedVac (Savant Instruments, Halbrook, NY) and reconstituted in $400 \mu 10.1 \%$ formic acid for LC/MS/MS analysis according to the quantification method of L-DOPA.

\subsection{Synthesis of $\left[{ }^{2} \mathrm{H}_{8}\right]$ NADA following injection of $\left[{ }^{2} \mathrm{H}_{8}\right]$ NA-L-DOPA in rat striatum}

All Rats ( $\mathrm{n}=5$ ) were anesthetized with ketamine/xylazine (73/8.8 mg/kg, i.p.), and $\left[{ }^{2} \mathrm{H}_{8}\right]$ NAL-DOPA was injected (total $1 \mathrm{nmol}$ in $1 \mu \mathrm{l}$ of 1:1:18 ethanol/emulphor/saline on ice) into the left striatum over a 1-min period (coordinates from bregma: anteroposterior, $+1.0 \mathrm{~mm}$; mediolateral, $-2.5 \mathrm{~mm}$; dorsoventral, $-6.2 \mathrm{~mm}$ from skull). After injection, the syringe was left in place for $1 \mathrm{~min}$ further before removal. The animals were then injected $0.1 \mathrm{ml}$ antisedan (an $\alpha 2$-adrenergic antagonist) intramuscularly to promote recovery from sedation. One hour after surgery, both left (experimental side) and right (control side) striata were removed and processed according to the NADA extraction procedure for further LC/MS/MS analysis as described above.

\subsection{Biosynthesis of NADA in rat brain membrane assays}

$\left[{ }^{2} \mathrm{H}_{8}\right]$ arachidonic acid $(20,50$, or $100 \mu \mathrm{M})$ with $\left[{ }^{2} \mathrm{H}_{4}\right]$ dopamine $(20,50$, or $100 \mu \mathrm{M})$ were incubated with rat $\mathrm{P}_{2}$ membranes (3 volumes brain weight total, $0.5 \mathrm{ml} 50 \mathrm{mM}$ Tris- $\mathrm{HCl}, 1$ mM EDTA, pH 7.4, also $0.17 \mathrm{mM}$ ascorbic acid, $6.7 \mathrm{mM}$ ATP, $0.1 \mathrm{mM}$ pargyline, and $1 \mu \mathrm{M}$ 
RO 41-0960) at $37^{\circ} \mathrm{C}$ for $25 \mathrm{~min}$. Buffer, boiled membrane, and non-incubated conditions were also tested. Following incubation, the preparation was extracted and analyzed by the procedure for NADA described above. Rat second pellet $\left(\mathrm{P}_{2}\right)$ brain membranes were prepared as described by Huang et al. [15].

\subsection{Experiments with arachidonoyl-CoA in homogenates}

For these experiments rat striatal, midbrain or hippocampal slices were homogenized in Tris$\mathrm{HCl}$ buffer $(50 \mathrm{mM}, \mathrm{pH} 7.4)$ containing $5 \mathrm{pmol}$ of $\left[{ }^{2} \mathrm{H}_{8}\right]-\mathrm{NADA}$. The debris was eliminated by centrifugation at $1000 \times \mathrm{g}$ at $4{ }^{\circ} \mathrm{C}$ for $15 \mathrm{~min}$, and the homogenate was incubated with either: 1) arachidonoyl-CoA $(5,15,25,50 \mu \mathrm{M})+\left[2,5,6-{ }^{3} \mathrm{H}\right]$ dopamine $(1 \mu \mathrm{Ci}, 5.8 \mathrm{Ci} / \mathrm{mmol})+50 \mu \mathrm{M}$ dopamine in the presence or absence of ascorbic acid $(100 \mu \mathrm{M})$; or 2$)\left[1-{ }^{13} \mathrm{C}\right]$ arachidonoyl$\mathrm{CoA}(0.1 \mu \mathrm{Ci}, 55 \mathrm{mCi} / \mathrm{mmol})+50 \mu \mathrm{M}$ arachidonoyl-CoA $+50 \mathrm{mM}$ dopamine in the presence or absence of ascorbic acid $(100 \mu \mathrm{M})$, or thimerosal $\left(50 \mu \mathrm{M}\right.$, Sigma) or $\mathrm{CaCl}_{2}(1 \mathrm{mM})$. Either 200 or $500 \mu \mathrm{g}$ proteins were used in each experiment. The incubations were carried out for either 10 or $30 \mathrm{~min}$ at $37^{\circ} \mathrm{C}$. Homogenates that had been boiled for $5 \mathrm{~min}$ were used as negative controls. After blocking the incubation on ice, the homogenates were extracted three times with $\mathrm{CHCl}_{3}: \mathrm{CH}_{3} \mathrm{OH}(2: 1, \mathrm{v}: \mathrm{v})$ and the organic phase liophilized under a flow of nitrogen. The extracts were then analysed by reverse phase HPLC on a Supelco C18 column $(150 \times 4.6 \mathrm{~mm}$, particle size $5 \mu \mathrm{m})$ using $\mathrm{CH}_{3} \mathrm{OH}: \mathrm{H}_{2} \mathrm{O}: \mathrm{CH}_{3} \mathrm{OH}(80: 20: 0.1$, v:v:v) as the mobile phase at a flow rate of $1 \mathrm{ml} / \mathrm{min}$. Under this condition $\left[{ }^{2} \mathrm{H}_{8}\right] \mathrm{NADA}$ was eluted after $17 \mathrm{~min}$. The radioactivity present in each HPLC fraction was measured with a scintillation beta-counter, or else the fractions eluting between 15 and 19 min were pooled, liophilized and analysed by HPLC coupled to atmospheric pressure chemical ionization mass spectrometry as described previously [6]. The lower limit of detection for NADA using this method was $0.5 \mathrm{pmol}$ and was sufficient in previous studies to detect NADA following high potassium stimulation of midbrain slices [6].

\subsection{Experiments with radiolabeled arachidonic acid incorporated into the plasma membrane}

Confluent rat C6 glioma cells were incubated overnight with $\left[5,6,8,9,11,12,14,15-{ }^{3} \mathrm{H}\right]$ arachidonic acid $(0.1 \mu \mathrm{Ci} / \mathrm{ml}$ of medium, $208 \mathrm{Ci} / \mathrm{mmol})$. After washing with medium three times, cells were either: 1) homogenated in Tris- $\mathrm{HCl}$ buffer $(50 \mathrm{mM}, \mathrm{pH} 7.4)$, and the homogenate incubated with $100 \mu \mathrm{M}$ dopamine for $0,5,30$ and 60 min at $37^{\circ} \mathrm{C}$, or 2) directly incubated with $100 \mu \mathrm{M}$ dopamine for $0,5,30$ and $60 \mathrm{~min}$ at $37^{\circ} \mathrm{C}$ either in the presence or absence of ionomycin $(4 \mu \mathrm{M})$. In either case, homogenates or cells were extracted three times with $\mathrm{CHCl}_{3}: \mathrm{CH}_{3} \mathrm{OH}(2: 1, \mathrm{v}: \mathrm{v})$, the extract spiked with 5 pmol $\left[{ }^{2} \mathrm{H}_{8}\right] \mathrm{NADA}$ and the organic phase liophilized under a flow of nitrogen. The extracts were then analysed by reverse phase HPLC as described above, and the radioactivity present in the HPLC fractions eluting a synthetic standard of 2-arachidonoyl glycerol (2-AG) (retention time $14 \mathrm{~min}$ ) or measured with a scintillation beta-counter.

\subsection{Effects of FAAH inhibition on striatal levels of AEA and NADA}

Animals were injected with either URB597 (0.3 mg/kg, in 1\% DMSO, i.p.) or vehicle. After two hours animals were decapitated and striata were dissected and flash-frozen in liquid nitrogen, extracted, purified and analyzed as described above.

\subsection{Analysis of striatal extracts from FAAH knockout and wild-type mice}

FAAH knockout and wild-type mice were sacrificed when they were 6 weeks old. The striata were dissected and stored at $-80{ }^{\circ} \mathrm{C}$ until used. Lipid extraction, partial purification, and quantitation were performed with methods identical to those described above. 


\subsection{Recombinant FAAH cell-free assay}

To determine the rates of hydrolysis a solution of ethanol and compound $(400 \mu \mathrm{M}, 10 \mu \mathrm{l})$ was added to a solution of recombinant FAAH protein $(10 \mu \mathrm{l}, 1.3 \mu \mathrm{g} / \mu 1$ in $20 \mathrm{mM}$ HEPES (pH 7.8), $150 \mathrm{mM} \mathrm{NaCl}, 10 \%$ glycerol, $1 \%$ Triton X-100) in buffer (Tris/EDTA, $380 \mu \mathrm{l}, \mathrm{pH}$ 9) at room temperature. A $40 \mu \mathrm{l}$ aliquot of the reaction mixture was taken at appropriate time points and quenched with $1 \mathrm{ml}$ of $\mathrm{MeOH}$. To control for loss of AEA and NADA to the sides of the tube and into micelles in the aqueous buffer, equal numbers of controls were run at the same time without FAAH. $1 \mu \mathrm{l}$ of the quenched solution from each (FAAH incubations and controls) was analyzed by LC/MS/MS mass spectrometry as discussed above. Hydrolysis rates were determined by the average values of the analyte measured from the FAAH incubations subtracted from the average values of the controls at each time point.

\subsection{Data analysis}

The quantitation of analytes was made via the Analyst software (Applied Biosystems-MDS Sciex; Framingham MA) quantitation wizard that quantifies the amount of analyte in femtomoles (fmol) per injection in an unknown sample based on the regression fit of known values from synthetic standards. Each of these comparisons was statistically analyzed using SPSS software (Chicago, IL). Statistical differences were determined using one-way analysis of variance (ANOVA). The effects of 6-OHDA on the striatal NADA levels were analyzed by nonparametric Wilcoxon signed-ranks tests because the NADA levels on the lesioned side dropped below our detection limit $(<1 \mathrm{fmol})$. The time-dependent effects of AMPT injection on striatal dopamine and NADA levels were first analyzed by one-way ANOVA and then the levels of striatal dopamine and NADA at each time point were compared with those of controls (time $=0 \mathrm{~min}$ ) respectively by using Dunnett post-hoc comparison. Data are presented as means \pm SE of the means where $p<0.05$ was considered statistically significant.

\section{Results}

\subsection{NADA biosynthesis in striatum requires dopaminergic terminals and TH}

NADA is most abundant in the striatum, which is the brain region with the greatest dopamine content, therefore we examined whether striatal NADA levels are dopamine-dependent. 6OHDA $(8 \mu \mathrm{g} / 4 \mu \mathrm{l})$ was injected into the left medial forebrain bundle to damage dopaminergic terminals and observed an $85 \%$ decrease in dopamine in the lesioned striatum (Fig. 2A). Correspondingly, the levels of NADA in the lesioned striatum fell below our detection limit $(<1 \mathrm{fmol})$ (Fig. 2B). This result suggested that NADA biosynthesis in the striatum requires dopaminergic terminals. However, because 6-OHDA lesions also deplete striatal TH, we next examined the role of $\mathrm{TH}$, the rate limiting enzyme in dopamine synthesis, in NADA biosynthesis.

To test if NADA biosynthesis requires TH, rats were injected with the TH inhibitor AMPT $(115 \mathrm{mg} / \mathrm{kg}$, i.p.), and striata were subsequently removed at 90, 180, 270, 360, and $450 \mathrm{~min}$ intervals. The control animals were injected with vehicle (distilled water) and immediately sacrificed. LC/MS/MS analysis revealed a time-dependent decrease in striatal levels of both dopamine, which fell to $44 \%$ of control and NADA, which fell to $27 \%$ of control, $360 \mathrm{~min}$ after AMPT injection supporting the involvement of TH in NADA biosynthesis (Fig. 3A and 3B).

\subsection{Identification of endogenous NA-tyrosine in rat brain}

$\mathrm{N}$-arachidonoyl-tyrosine (NA-tyrosine) is a potential NADA precursor; therefore, we examined the possibility that it is produced in the brain. Identification of NA-tyrosine (Fig. $4 \mathrm{~A}$ ) was accomplished using a partially purified brain lipid extract that was analyzed by nano- 
LC-quadrupole/time-of-flight mass spectrometry (nano-HPLC/QqTOF MS) and by chromatographic matching using LC/MS/MS. Nano-HPLC/QqTOF MS isolated a lipid compound within the brain extract with an exact mass of 466.3058, which is within 20 parts per million of the expected mass of NA-tyrosine (466.3038; Table 1). Additionally, the fragmentation pattern of the 466.3058 mass was the same as that produced by the synthetic standard (Fig. 4B), which is considered a mass fingerprint. Likewise, with LC/MS/MS using a technique that filters for the parent ion (466 amu) and pairs it with a predicted fragment (180 amu) a chromatographic match was revealed of a compound in the brain extract that matched with the NA-tyrosine standard (Fig. 4C). Taken together, these data supports the hypothesis that NA-tyrosine is produced in the brain.

\subsection{Examination of NA-tyrosine as a precursor of striatal NADA}

With the evidence that NA-tyrosine is present in the brain, we examined the possibility that NADA biosynthesis occurs via metabolism of NA-tyrosine to NA-L-DOPA by TH, which would then be metabolized to NADA by L-amino acid decarboxylase (AADC) (Fig. 1). NADA levels were significantly decreased $270 \mathrm{~min}$ after the TH inhibitor AMPT injection (Fig. 3B), therefore, we examined whether NA-tyrosine accumulated after TH inhibition. However, no significant increase was found, suggesting that NA-tyrosine may not be a substrate for TH in vivo. In order to substantiate this interpretation, we tested whether TH could convert NAtyrosine to NA-L-DOPA in vitro. We incubated L-tyrosine $(1 \mu \mathrm{M})$ or $\left[{ }^{2} \mathrm{H}_{8}\right] \mathrm{NA}$-tyrosine $(1$ $\mu \mathrm{M})$ with $\mathrm{TH}(16.5 \mu \mathrm{g})$ and examined the production of L-DOPA and $\left[{ }^{2} \mathrm{H}_{8}\right] \mathrm{NA}-\mathrm{L}-\mathrm{DOPA}$ by LC/MS/MS. The results indicated that $24.44 \%$ of L-tyrosine was converted to L-DOPA (24.44 pmol yield), whereas only $0.23 \%$ of $\left[{ }^{2} \mathrm{H}_{8}\right] \mathrm{NA}$-tyrosine was converted to $\left[{ }^{2} \mathrm{H}_{8}\right] \mathrm{NA}-\mathrm{L}-\mathrm{DOPA}$ ( 2.28 pmol yield), indicating that NA-tyrosine is a poor substrate for TH. Neither L-DOPA nor $\left[{ }^{2} \mathrm{H}_{8}\right]$ NA-L-DOPA were detected when buffer only or boiled enzyme were incubated with the respective precursors.

To test the hypothesis that NA-L-DOPA is a direct precursor to NADA, we measured the amount of $\left[{ }^{2} \mathrm{H}_{8}\right]$ NADA formed following injection of $\left[{ }^{2} \mathrm{H}_{8}\right]$ NA-L-DOPA in the rat striatum. There were no detectable levels of $\left[{ }^{2} \mathrm{H}_{8}\right] \mathrm{NADA}$ in either injected or non-injected striata, which implied that NA-L-DOPA is not converted to NADA in striatum. Together, these data indicated that it is unlikely that NADA biosynthesis occurs via metabolism of NA-tyrosine or NA-LDOPA.

\subsection{No detectable NADA is formed via arachidonoyl-CoA and dopamine incubation with brain membranes}

It is likely that NADA is formed via conjugation of arachidonoyl CoA and dopamine. However, when homogenates of striatal, midbrain or hippocampal rat slices were incubated with $50 \mu \mathrm{M}$ of $\left[{ }^{14} \mathrm{C}\right]$ arachidonoyl-CoA and $50 \mu \mathrm{M}$ dopamine, or with various concentrations $(5-50 \mu \mathrm{M})$ of arachidonoyl-CoA and $50 \mu \mathrm{M}$ of $\left[{ }^{3} \mathrm{H}\right]$ dopamine, and the incubated homogenate extracted and submitted to HPLC analysis, no radiolabeled peak co-eluting with NADA (retention time $17 \mathrm{~min}$ ) was observed with any of the conditions tested. Although the measurement of radioactivity in chromatographic fractions was previously shown to be sensitive enough to detect the enzymatic formation of radiolabeled NADA [1], we decided to also analyze the HPLC fraction at 16-18 min retention time by either positive or negative ion LC-APCI-MS. No peak at the $m / z$ expected from NADA or its loss was found. When the experiment was repeated in the presence of either $1 \mathrm{mM} \mathrm{Ca}^{2+}$ or $50 \mu \mathrm{M}$ thimerosal, to stimulate potential calcium-sensitive enzymes or to reduce arachidonoyl-CoA incorporation into phospholipids and triacylglycerols and diacylglycerol, similar negative results were obtained. Finally, when ascorbic acid was included in the reaction to inhibit dopamine oxidation, still no NADA-like material was found. 


\subsection{No detectable NADA is formed via arachidonic acid esterified to phospholipids incubated with $\mathrm{C6}$ glioma cells}

Rat C6 glioma cells were incubated overnight with $\left[{ }^{3} \mathrm{H}\right]$ arachidonic acid in order to allow its incorporation into membrane phospholipids. They were then incubated at $37^{\circ} \mathrm{C}$ for increasing periods of time (0-60 min) with $100 \mu \mathrm{M}$ dopamine, either in the presence or absence of ionomycin $(4 \mu \mathrm{M})$ to stimulate $\mathrm{Ca}^{2+}$ influx into the cells. Under these conditions no formation of tritiated NADA-like components in cell homogenates were observed using HPLC analysis. Under similar conditions, $\left[{ }^{3} \mathrm{H}\right] 2$-arachidonoylglycerol $\left(\left[{ }^{3} \mathrm{H}\right] 2-\mathrm{AG}\right)$ was formed following stimulation with $4 \mu \mathrm{M}$ ionomycin (data not shown). Analogous negative results were obtained when whole cell homogenates from radiolabeled C6 cells were incubated at $37^{\circ} \mathrm{C}$ for increasing periods of time (0-60 min) with $100 \mu \mathrm{M}$ dopamine.

\subsection{NADA biosynthesis occurs via conjugation of arachidonic acid with dopamine in rat brain membranes}

Previously, the hypothesis that NADA could be formed by conjugation of arachidonic acid with dopamine was examined using radiolabeled precursors and TLC characterization of the enzymatic products [9]. In the current study, the possibility that NADA biosynthesis occurs through conjugation of arachidonic acid with dopamine was investigated quantitatively by incubating rat brain membranes with 20,50 , and $100 \mu \mathrm{M}\left[{ }^{2} \mathrm{H}_{8}\right]$ arachidonic acid and 20, 50, and $100 \mu \mathrm{M}\left[{ }^{2} \mathrm{H}_{4}\right]$ dopamine at $37{ }^{\circ} \mathrm{C}$ for $25 \mathrm{~min}$, respectively. Here we found that when rat brain membranes were incubated with $\left[{ }^{2} \mathrm{H}_{8}\right]$ arachidonic acid and $\left[{ }^{2} \mathrm{H}_{4}\right]$ dopamine, deuterated NADA was produced and detectable at masses corresponding to molecular ions ranging from $\left[{ }^{2} \mathrm{H}_{8}\right] \mathrm{NADA}$ to $\left[{ }^{2} \mathrm{H}_{12}\right] \mathrm{NADA}$ (the varying degree of deuterium incorporation is expected due to proton exchange with the aqueous buffer and the tissue). The production of $\left[{ }^{2} \mathrm{H}_{12}\right]$ - and $\left[{ }^{2} \mathrm{H}_{11}\right] \mathrm{NADA}$ molecular ions was concentration-dependent with higher concentrations of precursors leading to higher concentrations of product (Fig. 5). An enzymatic mechanism is likely as deuterated NADA was not detected when the substrates were incubated with buffer alone or with boiled membranes (Fig. 5). These results indicate that NADA can be synthesized through the enzymatic conjugation of arachidonic acid and dopamine via an enzymatic process.

\subsection{Endogenous level of striatal NADA after URB597 injections in rats and in FAAH knockout and wild-type mice}

To determine whether FAAH modulates endogenous NADA levels, we examined AEA and NADA levels in rats treated with URB597 or vehicle and in FAAH knockout and wild-type mice. The levels of AEA in rat striatum significantly increased 2 hours after systemic injection of the FAAH inhibitor URB597 ( $0.3 \mathrm{mg} / \mathrm{kg}$ ) compared to vehicle controls (Fig. 6A). In contrast, striatal levels of NADA significantly decreased (Fig. 6A). The same pattern was observed in the striatal levels of AEA and NADA in FAAH knockout and wild-type mice: AEA levels were significantly higher whereas NADA levels were significantly lower in striata from FAAH knockout mice (Fig. 6B).

\subsection{NADA is a poor substrate for recombinant FAAH}

The evidence that NADA levels were significantly decreased with FAAH inhibition and in FAAH knockout mice led us to test the hypothesis that: 1) FAAH is acting as a biosynthetic enzyme with AEA and dopamine as precursors, and 2) NADA is a poor substrate for FAAH. If NADA is a high-affinity substrate for FAAH producing robust levels of hydrolysis, then it is unlikely to play a role in its biosynthesis. Conversely, if AEA is converted to NADA during hydrolysis in the presence of dopamine, then FAAH would in fact be a candidate enzyme for NADA biosynthesis. Our results show that when recombinant FAAH was incubated with AEA and dopamine, AEA was measured via HPLC/MS/MS and was shown to be rapidly hydrolyzed as expected (Fig 7 A). At 3 minutes $\sim 80 \%$ of all AEA was hydrolyzed and by $\sim 10$ minutes 
over 95\%. At 30 minutes there was almost no detectable AEA present in the solution.

Conversely, at 3 minutes less than 10\% of NADA was hydrolyzed and at 30 minutes there was still over $50 \%$ of NADA still left in the solution. Surprisingly, trace amounts of NADA were produced in a time-dependent manner when AEA and dopamine were incubated with FAAH. Small amounts of NADA were detected throughout the incubation during the first 15 minutes and at 30 minutes, when there was no detectable AEA (therefore, an abundance of liberated arachidonic acid), and up to $~ 3 \%$ of NADA production was measured (mole for mole compared to a theoretical $100 \%$ AEA). To control for any carry-over or MS contamination of NADA, which has a history of carry-over on columns and in tubing (unpublished observations), we used new columns and tubing and performed the recombinant FAAH incubations with deuterium-labeled NADA $\left(\left[\mathrm{H}_{8}\right]\right.$ NADA; Fig.7A). Therefore, the NADA that was measured via HPLC/MS/MS after incubation of AEA and dopamine with recombinant FAAH could not be carry-over contaminants.

\section{Discussion}

In the present study we investigated several biosynthetic mechanisms for NADA and report that NADA synthesis requires TH in dopaminergic terminals and occurs through an enzymemediated conjugation of arachidonic acid with dopamine and not through the endogenous NAtyrosine. One enzyme involved in the biosynthetic process is fatty acid amide hydrolase, FAAH, the blockade of which significantly decreases in vivo the production of NADA.

Lesion studies of the striatum supported the hypothesis that NADA is synthesized in dopaminergic terminals where TH is located. One potential implication of the significant decrease in NADA production measured after striatal lesions is that the $\mathrm{K}_{\mathrm{m}}$ of the conjugation reaction for dopamine is high, so that small decreases in dopamine concentration may lead to large decreases in NADA. However, this has not been examined in vitro.

We originally proposed two potential pathways for NADA biosynthesis: one mediated by metabolism of the putative precursor NA-tyrosine; the other via direct conjugation of arachidonic acid with dopamine [1]. However, based on the lesion studies presented here, it is hard to distinguish which of these two pathways is dominant in NADA biosynthesis since the essential molecular component for both pathways, TH, was depleted under conditions of dopaminergic terminal destruction or TH inhibition. To elucidate the primary pathway in NADA biosynthesis, we determined that NA-tyrosine is a naturally occurring molecule in the rat, a conclusion based upon mass spectrometric analysis (LC/MS/MS and nano-HPLC/ QqTOF), showing that the exact masses, column retention times and fragmentation patterns of the constituent found in rat brain were virtually identical to those of NA-tyrosine. Although our results support the existence of endogenous NA-tyrosine, which could be a precursor for NADA biosynthesis via $\mathrm{TH}$, our data did not support the hypothesis that NA-tyrosine is a precursor for NADA biosynthesis given the following: (1) NA-tyrosine did not accumulate after TH inhibition, (2) incubating deuterium-labeled NA-tyrosine with purified recombinant TH failed to produce deuterated NA-L-DOPA and, (3) the injection of deuterium-labeled NAL-DOPA into striatum failed to produce deuterated NADA. These results suggest that NAtyrosine is a poor substrate for TH in vivo and in vitro and that the presence of NA-tyrosine in rat brain might have little to do with NADA biosynthesis. Rather, it is possible that endogenous NA-tyrosine is an endogenous signaling molecule with a separate function to NADA and/or a mediator for biosynthesis of other $N$-arachidonoyl amino acids, such as the previously identified conjugates of arachidonic acid with glycine, alanine, $\gamma$-amino-butyric acid, and serine $[15,16]$. However, it is important to keep in mind that the possibility of NA-tyrosine conversion into NA-L-DOPA by enzymes other than TH in vivo cannot be ruled out by the above results. It is also possible, though unlikely, that the failed production of NADA from NA-L-DOPA injection may due to compartmentalization. A faster degradation of exogenous 
NA-L-DOPA than its uptake into cells and then conversion into NADA may also explain the negative findings in the current study.

Confirmed here is the hypothesis that NADA is synthesized via conjugation of arachidonic acid and dopamine through an enzyme-dependent process. Whether or not intermediates are formed as part of this process remains uncertain. Although little is known about the enzyme (s) involved in NADA biosynthesis, Huang and colleagues [1] proposed a possible mechanism similar to the formation of $\mathrm{N}$-arachidonoyl glycine (NAGly) [10]. The enzyme, arachidonoylCoA synthetase, which belongs to an enzymatic family of acyl-CoA synthetase, converts arachidonic acid into arachidonoyl-CoA in the brain, platelets, and aorta [17-19]. A second family of enzymes, the acyl-coenzyme A:glycine $N$-acyltransferases, may conjugate glycine to various aliphatic and aromatic acyl-CoAs [20-25]. Here, we tested the possible role of arachidonoyl-CoA in the direct formation of NADA and were unable to produce NADA under several experimental conditions. Likewise, we did not observe the formation of any NADAlike HPLC component from arachidonic acid incorporated into phospholipids when using either intact cell or cell-free conditions. It is possible that the bioavailability of these intermediates is an issue and that the biosynthetic process is such that there is a rate-limiting step that initiates the production of NADA and in the absence of this step NADA would not be formed even with an excess of substrate.

A recent report showed that FAAH can participate in the in vivo synthesis of AM404 by conjugation of arachidonic acid to exogenously administered acetaminophen [9]. We examined if striatal levels of NADA were changed after pharmacological or genetic inhibition of FAAH. That the normal NADA levels in rat striatum could be so dramatically decreased with FAAH inhibition and that FAAH knockout mice have significantly less NADA than wide-type mice was convincing evidence that FAAH was in some way involved in the biosynthesis of NADA. Accordingly, FAAH mRNA is moderately expressed in striatum and FAAH activity is detectable in rat striatum [26]. Also, an increased level of striatal AEA and a decreased activity of FAAH were observed after destruction of dopaminergic terminals by 6-OHDA [27]. These data support the possibility that FAAH has the potential to be involved in the direct conjugation of dopamine with arachidonic acid liberated from AEA, and is the rate-limiting enzyme for NADA biosynthesis. Alternately, the decreased levels of striatal NADA by FAAH inhibition or depletion may result from elevation of AEA concentrations in the striatum. Maccarrone and colleagues [28] reported that elevation of AEA concentrations in the striatum by FAAH inhibition or depletion reduced the levels, metabolism and physiological effects of 2-AG. It is possible that elevated striatal AEA has modulatory effects on metabolism of NADA, thereby reducing its levels in the striatum, and future studies will address this issue.

Early studies showed that AEA can be synthesized by conjugation of arachidonic acid and ethanolamine and this reaction might be catalyzed by FAAH acting in reverse $[29,30]$. However, this pathway was later shown to be unlikely given that AEA is an excellent substrate for FAAH (also confirmed here), thus the rate of AEA hydrolysis by FAAH was much greater than AEA synthesis from the conjugation of arachidonic acid and ethanolamine. Later research found that there are at least three potential pathways involved in AEA biosynthesis that includes several novel enzymes such as $N$-acyl phosphatidylethanolamine phospholipase D (NAPEPLD), glycerophosphodiesterase (GDE1), $\alpha / \beta$ hydrolase 4 (ABHD4) or an unknown phosphatase [31-35]. To date, there are no known $N$-acyl phosphatidyldopamines, so these analogous pathways are highly unlikely.

The possibility that FAAH is a candidate for an enzyme complex involved in NADA biosynthesis is in further agreement with the observation that NADA is a poor substrate for FAAH [1]. We confirmed this observation here and showed that the rate of hydrolysis of NADA by FAAH is dramatically lower than that of AEA ( 7 fold at 3 minutes and 5 fold at 30 minutes). 
When AEA was incubated with FAAH in the presence of dopamine, NADA was synthesized in trace amounts. Our HPLC/MS/MS method for detection of NADA is 500 atamoles and, therefore, the most sensitive published to date. In fact, previous methods used in this study for our earlier assays would not have detected these trace amounts. The largest amount of production of NADA ( $3 \%$ ) was at 30 minutes when there were only trace amounts of AEA left in the solution, so that the substrates available were arachidonic acid and dopamine. Given that FAAH is an integral membrane protein and that recombinant FAAH is in an unbound state in vitro, it is unlikely to act in exactly the same manner as the bound state in vivo. It is difficult to determine if the synthesis of NADA in vitro represents the result of an energetically favorable reaction or the result of FAAH acting as a biosynthetic enzyme at a sub-optimal level given that its conformation is potentially different from that in the membrane-bound form. Future studies will address this issue.

In conclusion, we report here in vitro and in vivo evidence that NADA biosynthesis in rat brain depends on TH in dopaminergic terminals and that this endocannabinoid/endovanilloid can be made from the conjugation of dopamine with arachidonic acid, but that it is likely not formed via NA-tyrosine and NA-L-DOPA intermediates. Our data suggest a direct involvement of FAAH in NADA biosynthesis as either a rate-limiting enzyme that liberates arachidonic acid from AEA, as a conjugation enzyme, or both. Further investigations are needed to elucidate the exact molecular details of this enzymatic process.

\section{Acknowledgements}

This work is dedicated to Dr. J. Michael Walker (1950-2008) whose love of science was an inspiration to us all. We are grateful for Dr. Ken Mackie's comments on the manuscript. We thank Dr. Filomena Fezza (University of Rome "Tor Vergata", Italy) and Dr. Mauro Maccarrone (University of Teramo, Italy) for their valuable help in the initial phase of this study and Jocelyn F. Krey for the technical assistance.

This study was supported by grants from National Institutes on Drug Abuse (DA13012 to JMW), the Gill Center for Biomolecular Science, Indiana University, Bloomington, the Lilly Foundation Inc., Indianapolis, IN, and by the VolkswagenStiftung (to VDM).

\section{Abbreviations}

NADA, $N$-arachidonoyl dopamine

NA-tyrosine, $N$-arachidonoyl tyrosine

NA-DOPA, $N$-arachidonoyl-L-DOPA

NAGly, $N$-arachidonoyl glycine

AM404, $N$-arachidonoyl phenolamine

$\mathrm{TH}$, tyrosine hydroxylase

AADC, L-amino acid decarboxylase

6-OHDA, 6-hydroxydopamine

AMPT, DL- $\alpha$-methyl-para-tyrosine methyl ester

TRPV1, transient receptor potential vanilloid type 1 channels

$\mathrm{CB}_{1}$ receptors, cannabinoid receptor type 1

DTT, dithiothreitol

$\mathrm{BH}_{4}$, tetrahydrobiopterin

COMT, catechol-O-methyltransferase

MAO, monoamine oxidase

ATP, adenosine 5'-triphosphate

HPLC, high performance liquid chromatography

LC/MS/MS, liquid chromatography/triple quadrupole tandem mass spectrometry

MRM, multiple reaction monitoring 


\section{References}

1. Huang SM, Bisogno T, Trevisani M, Al-Hayani A, De Petrocellis L, Fezza F, Tognetto M, Petros TJ, Krey JF, Chu CJ, Miller JD, Davies SN, Geppetti P, Walker JM, Di Marzo V. An endogenous capsaicin-like substance with high potency at recombinant and native vanilloid VR1 receptors. Proc. Natl. Acad. Sci. USA 2002;99:8400-8405. [PubMed: 12060783]

2. Bezuglov V, Bobrov M, Gretskaya N, Gonchar A, Zinchenko G, Melck D, Bisogno T, Di Marzo V, Kuklev D, Rossi JC, Vidal JP, Durand T, Bobrov MYu, Gretskaya NM, Bezuglov VV, De Petrocellis L. Synthesis and biological evaluation of novel amides of polyunsaturated fatty acids with dopamine. Bioorg. Med. Chem. Lett 2001;11:447-449. [PubMed: 11229744]

3. Bisogno T, Melck D, Bobrov MYu, Gretskaya NM, Bezuglov VV, De Petrocellis L, Di Marzo V. Nacyl-dopamines: novel synthetic $\mathrm{CB}(1)$ cannabinoid-receptor ligands and inhibitors of anandamide inactivation with cannabimimetic activity in vitro and in vivo. Biochem. J 2000;351:817-824. [PubMed: 11042139]

4. Sagar DR, Smith PA, Millns PJ, Smart D, Kendall DA, Chapman V. TRPV1 and CB(1) receptormediated effects of the endovanilloid/endocannabinoid $N$-arachidonoyl-dopamine on primary afferent fibre and spinal cord neuronal responses in the rat. Eur. J. Neurosci 2004;20:175-184. [PubMed: 15245490]

5. O'Sullivan SE, Kendall DA, Randall MD. Vascular effects of delta 9-tetrahydrocannabinol (THC), anandamide and $\mathrm{N}$-arachidonoyldopamine (NADA) in the rat isolated aorta. Eur. J. Pharmacol 2005;507:211-221. [PubMed: 15659311]

6. Marinelli S, Di Marzo V, Florenzano F, Fezza F, Viscomi MT, van der Stelt M, Bernardi G, Molinari M, Maccarrone M, Mercuri NB. N-Arachidonoyl-dopamine tunes synaptic transmission onto dopaminergic neurons by activating both cannabinoid and vanilloid receptors. Neuropsychophar 2007;32:298-308.

7. Huang SM, Walker JM. Enhancement of spontaneous and heat-evoked activity in spinal nociceptive neurons by the endovanilloid/endocannabinoid $N$-arachidonoyldopamine (NADA). J. Neurophysiol 2006;95:1207-1212. [PubMed: 16267120]

8. Pajouhesh H, Hancock AJ. Synthesis of cyclopentano-Nmethylphosphatidylethanolamines: aminolysis during the use of methylamine. J. Lipid Res 1984;25:310-312. [PubMed: 6726084]

9. Högestätt ED, Jönsson BA, Ermund A, Andersson DA, Björk H, Alexander JP, Cravatt BF, Basbaum AI, Zygmunt PM. Conversion of acetaminophen to the bioactive $N$-acylphenolamine AM404 via fatty acid amide hydrolase-dependent arachidonic acid conjugation in the nervous system. J. Biol. Chem 2005;280:31405-31412. [PubMed: 15987694]

10. Cravatt BF, Demarest K, Patricelli MP, Bracey MH, Giang DK, Martin BR, Lichtman AH. Supersensitivity to anandamide and enhanced endogenous cannabinoid signaling in mice lacking fatty acid amide hydrolase. Proc. Natl. Acad. Sci. USA 2001;98:9371-9376. [PubMed: 11470906]

11. Gahn LG, Roskoski R Jr. Tyrosine hydroxylase purification from rat PC12 cells. Protein Expr. Purif 1991;2:10-14. [PubMed: 1687981]

12. Grazia Cascio M, Minassi A, Ligresti A, Appendino G, Burstein S, Di Marzo V. A structure-activity relationship study on $\mathrm{N}$-arachidonoyl-amino acids as possible endogenous inhibitors of fatty acid amide hydrolase. Biochem. Biophys. Res. Commun 2004;314:192-196. [PubMed: 14715265]

13. Rimmerman N, Bradshaw HB, Hughes HV, Chen JS, Hu SS, McHugh D, Vefring E, Jahnsen JA, Thompson EL, Masuda K, Cravatt BF, Burstein S, Vasko MR, Prieto AL, O'Dell DK, Walker JM. $N$-Palmitoyl glycine, a novel endogenous lipid that acts as a modulator of calcium influx and nitric oxide production in sensory neurons. Mol. Pharmacol 2008;74:213-224. [PubMed: 18424551]

14. Schechter MD, Cook PG. Dopaminergic mediation of the interoceptive cue produced by damphetamine in rats. Psychopharmacologia 1975;42:185-193. [PubMed: 240181]

15. Huang SM, Bisogno T, Petros TJ, Chang SY, Zavitsanos PA, Zipkin RE, Sivakumar R, Coop A, Maeda DY, De Petrocellis L, Burstein S, Di Marzo V, Walker JM. Identification of a new class of molecules, the arachidonyl amino acids, and characterization of one member that inhibits pain. J. Biol. Chem 2001;276:42639-42644. [PubMed: 11518719]

16. Milman G, Maor Y, Abu-Lafi S, Horowitz M, Gallily R, Batkai S, Mo FM, Offertaler L, Pacher P, Kunos G, Mechoulam R. $N$-arachidonoyl L-serine, an endocannabinoid-like brain constituent with vasodilatory properties. Proc. Natl. Acad. Sci. USA 2006;103:2428-2433. [PubMed: 16467152] 
17. Reddy TS, Bazan NG. Kinetic properties of arachidonoyl-coenzyme A synthetase in rat brain microsomes. Arch. Biochem. Biophys 1983;226:125-133. [PubMed: 6639046]

18. Wilson DB, Prescott SM, Majerus PW. Discovery of an arachidonoyl coenzyme A synthetase in human platelets. J. Biol. Chem 1982;257:3510-3515. [PubMed: 7061494]

19. Morisaki N, Saito Y, Kumagai A. Synthesis and metabolism of arachidonyl- and eicosapentaenoylCoA in rat aorta. Biochim. Biophys. Acta 1983;752:301-306. [PubMed: 6305425]

20. Schachter D, Taggart JV. Benzoyl coenzyme A and hippurate synthesis. J. Biol. Chem 1953;203:925934. [PubMed: 13084662]

21. Schachter D, Taggart JV. Glycine $N$-acylase: purification and properties. J. Biol. Chem 1954;208:263-275. [PubMed: 13174534]

22. Nandi DL, Lucas SV, Webster LT. Benzoyl-coenzyme A:glycine $N$-acyltransferase and phenylacetylcoenzyme A:glycine $N$-acyltransferase from bovine liver mitochondria. Purification and characterization. J. Biol. Chem 1979;254:7230-7237. [PubMed: 457678]

23. Kølvraa S, Gregersen N. Acyl-CoA:glycine $N$-acyltransferase: organelle localization and affinity toward straight- and branched-chained acyl-CoA esters in rat liver. Biochem. Med. Metab. Biol 1986;36:98-105. [PubMed: 3741707]

24. Gregersen N, Kølvraa S, Mortensen PB. Acyl-CoA: glycine $N$-acyltransferase: in vitro studies on the glycine conjugation of straight- and branched-chained acyl-CoA esters in human liver. Biochem. Med. Metab. Biol 1986;35:210-218. [PubMed: 3707752]

25. Mawal YR, Qureshi IA. Purification to homogeneity of mitochondrial acyl CoA: glycine $N$ acyltransferase from human liver. Biochem. Biophys. Res. Commun 1994;205:1373-1379. [PubMed: 7802672]

26. Thomas EA, Cravatt BF, Danielson PE, Gilula NB, Sutcliffe JG. Fatty acid amide hydrolase, the degradative enzyme for anandamide and oleamide, has selective distribution in neurons within the rat central nervous system. J. Neurosci. Res 1997;50:1047-1052. [PubMed: 9452020]

27. Gubellini P, Picconi B, Bari M, Battista N, Calabresi P, Centonze D, Bernardi G, Finazzi-Agrò A, Maccarrone M. Experimental parkinsonism alters endocannabinoid degradation: implications for striatal glutamatergic transmission. J. Neurosci 2002;22:6900-6907. [PubMed: 12177188]

28. Maccarrone M, Rossi S, Bari M, De Chiara V, Fezza F, Musella A, Gasperi V, Prosperetti C, Bernardi G, Finazzi-Agrò A, Cravatt BF, Centonze D. Anandamide inhibits metabolism and physiological actions of 2-arachidonoylglycerol in the striatum. Nat. Neurosci 2008;11:152-159. [PubMed: 18204441]

29. Devane WA, Axelrod J. Enzymatic synthesis of anandamide, an endogenous ligand for the cannabinoid receptor, by brain membranes. Proc. Natl. Acad. Sci. USA 1994;91:6698-6701. [PubMed: 8022836]

30. Arreaza G, Devane WA, Omeir RL, Sajnani G, Kunz J, Cravatt BF, Deutsch DG. The cloned rat hydrolytic enzyme responsible for the breakdown of anandamide also catalyzes its formation via the condensation of arachidonic acid and ethanolamine. Neurosci. Lett 1997;234:59-62. [PubMed: 9347946]

31. Ahn K, McKinney MK, Cravatt BF. Enzymatic pathways that regulate endocannabinoid signaling in the nervous system. Chem. Rev 2008;108:1687-1707. [PubMed: 18429637]

32. Okamoto Y, Morishita J, Tsuboi K, Tonai T. N. Ueda Molecular characterization of a phospholipase D generating anandamide and its congeners. J. Biol. Chem 2004;279:5298-5305. [PubMed: 14634025]

33. Leung D, Saghatelian A, Simon GM, Cravatt BF. Inactivation of $N$-acyl phosphatidylethanolamine phospholipase D reveals multiple mechanisms for the biosynthesis of endocannabinoids. Biochemistry 2006;45:4720-4726. [PubMed: 16605240]

34. Simon GM, Cravatt BF. Endocannabinoid biosynthesis proceeding through glycerophospho- $N$-acyl ethanolamine and a role for alpha/beta-hydrolase 4 in this pathway. J. Biol. Chem 2006;281:2646526472. [PubMed: 16818490]

35. Simon GM, Cravatt BF. Anandamide biosynthesis catalyzed by the phosphodiesterase GDE1 and detection of glycerophospho- $N$-acyl ethanolamine precursors in mouse brain. J. Biol. Chem 2008;283:9341-9349. [PubMed: 18227059] 


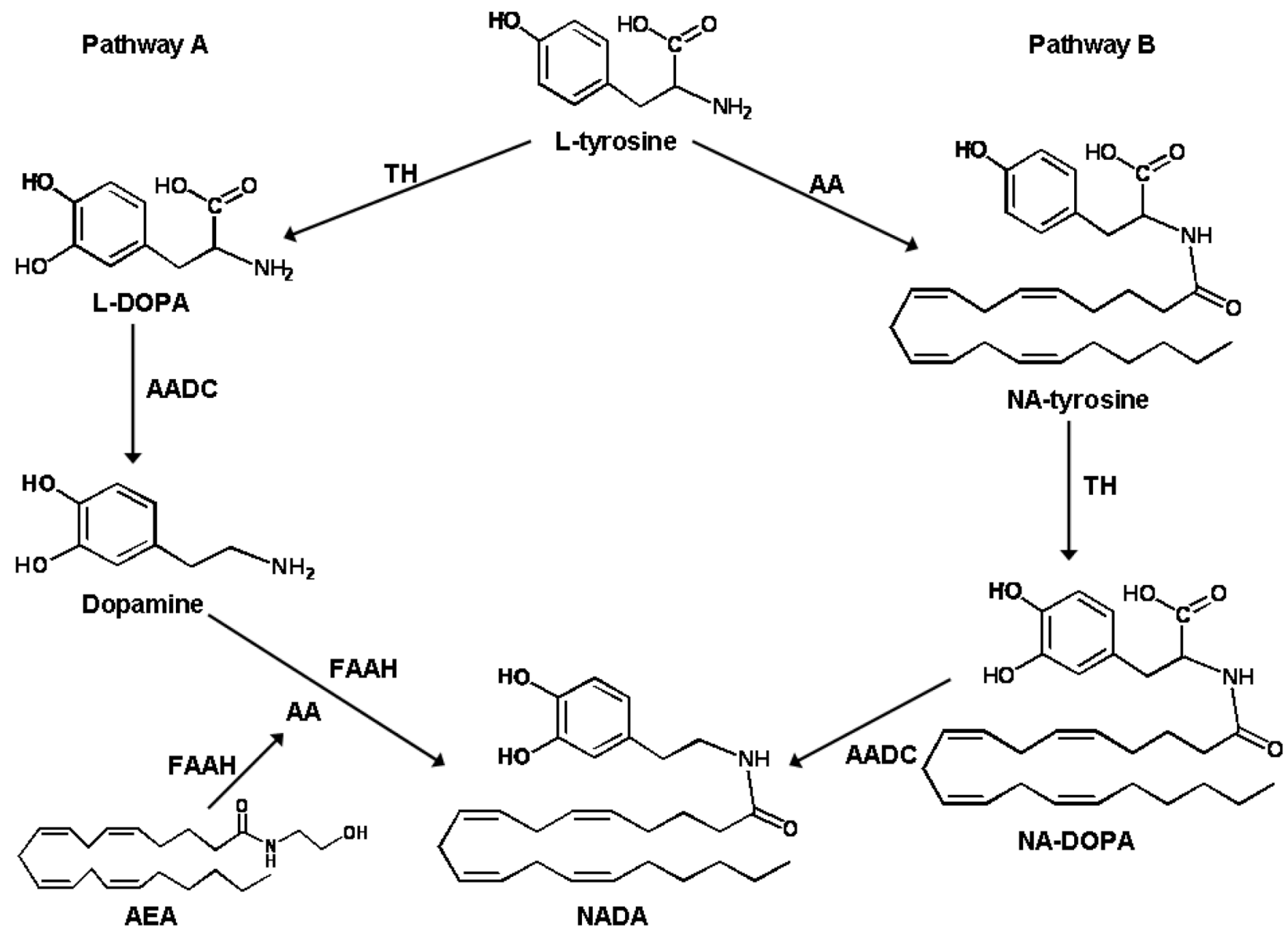

Figure 1.

Two potential pathways for NADA biosynthesis. Pathway A involves conjugation of dopamine with arachidonic acid (AA). Pathway B involves NA-tyrosine, hypothesized to be metabolized sequentially by TH and AADC to form NA-DOPA and NADA, respectively. 
(A)

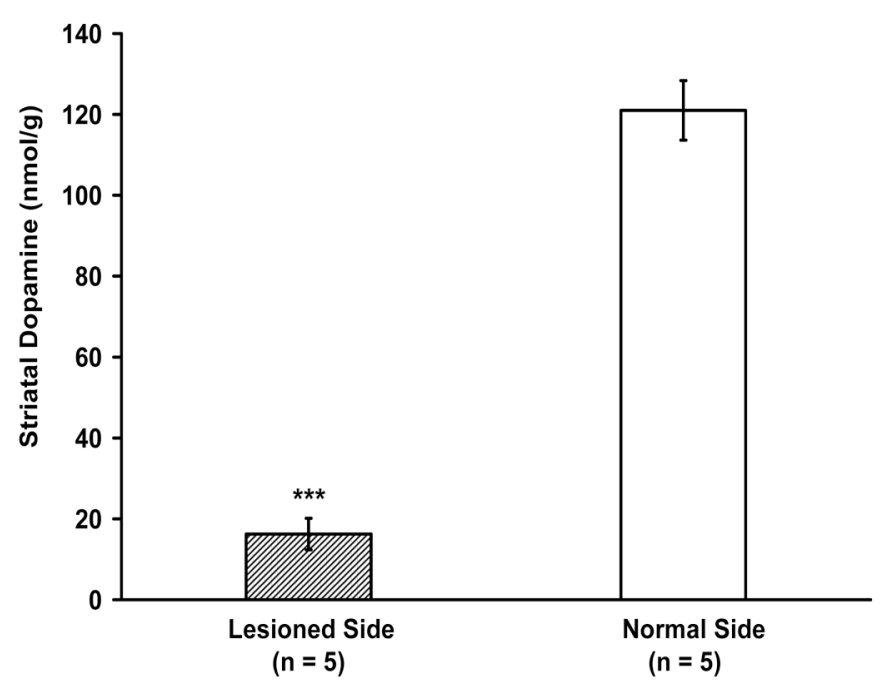

(B)

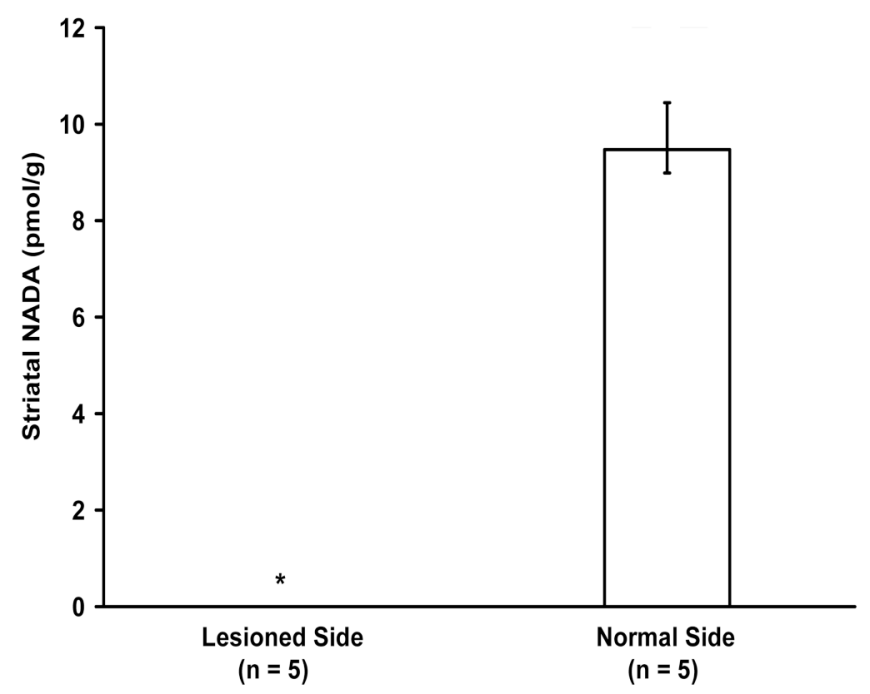

Figure 2.

Effect of nigrostriatal dopaminergic terminals lesion by 6-OHDA $(8 \mu \mathrm{g} / 4 \mu \mathrm{l})$ on levels of dopamine and NADA in rat striata $(n=5)$. (A) $85 \%$ depletion of dopamine was found in the lesioned striata (mean dopamine level on lesioned side $=16 \mathrm{nmol} / \mathrm{g}$ of striatum vs. mean dopamine level on untreated side $=121 \mathrm{nmol} / \mathrm{g}$ of striatum, $* * * p<0.0005)$. (B) The levels of NADA in the lesioned striata fell below our detection limit $(<1 \mathrm{fmol})$ (mean NADA level on lesioned side $<1 \mathrm{fmol} / \mathrm{g}$ striatum vs. mean NADA level on untreated side $=1894 \mathrm{fmol} / \mathrm{g}$ striatum, $* p<0.05$, nonparametric Wilcoxon signed-ranks tests). 
(A)

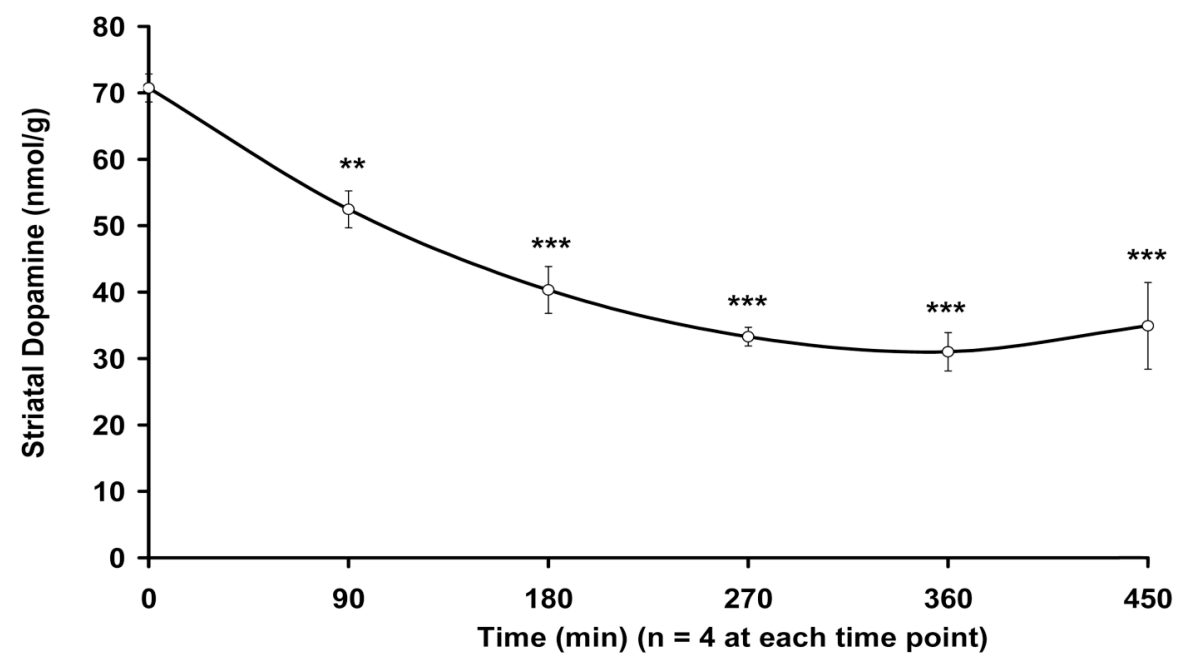

(B)

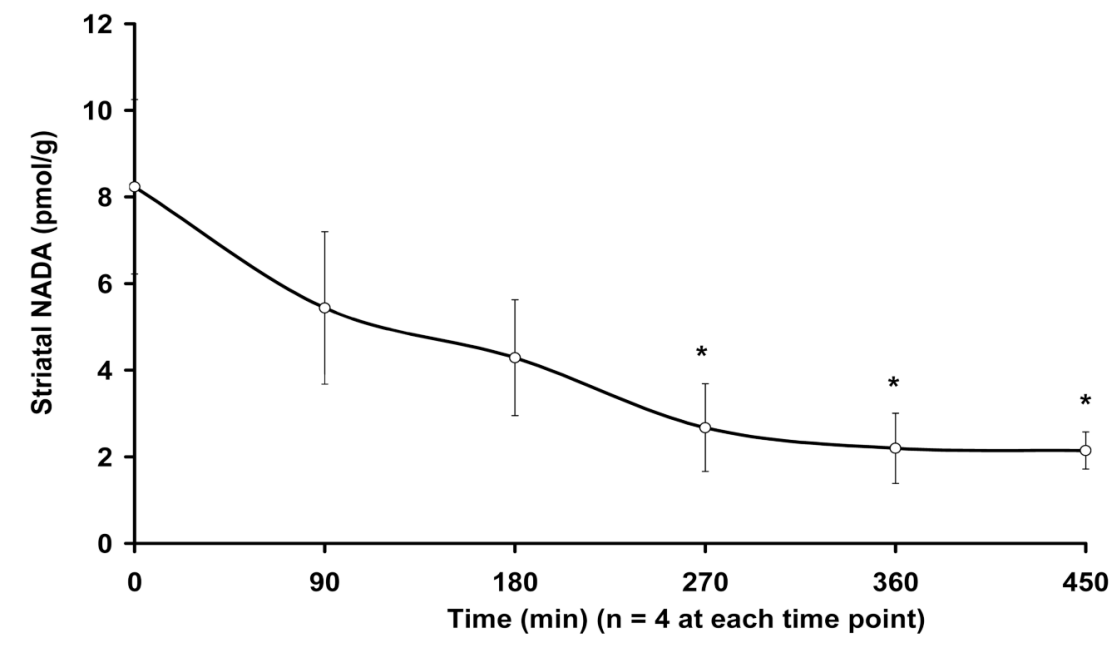

Figure 3.

The TH inhibitor AMPT decreases dopamine and NADA levels in rat striata in a timedependent fashion. (A) A time-dependent decrease in striatal levels of dopamine was observed when compared to control (time $=0)(* * p<0.01$ at $90 \mathrm{~min} ; * * * p<0.0005$ at $180,270,360$, and $450 \mathrm{~min}$ ). (B) A time-dependent decrease in striatal levels of NADA was also observed when compared to control (time $=0)(* p<0.05$ at 270,360 , and $450 \min )(\mathrm{n}=4$ at each time point). 
(A) N-Arachidonoyl tyrosine (NA-tyrosine)

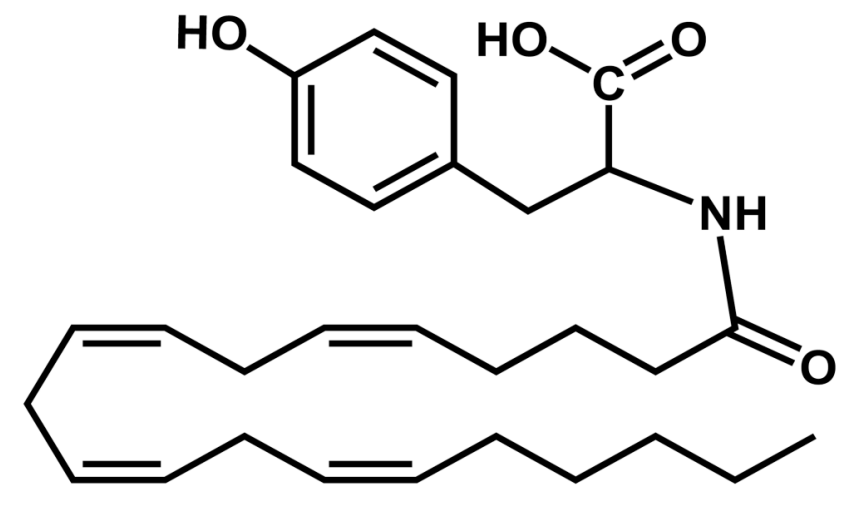

(B)

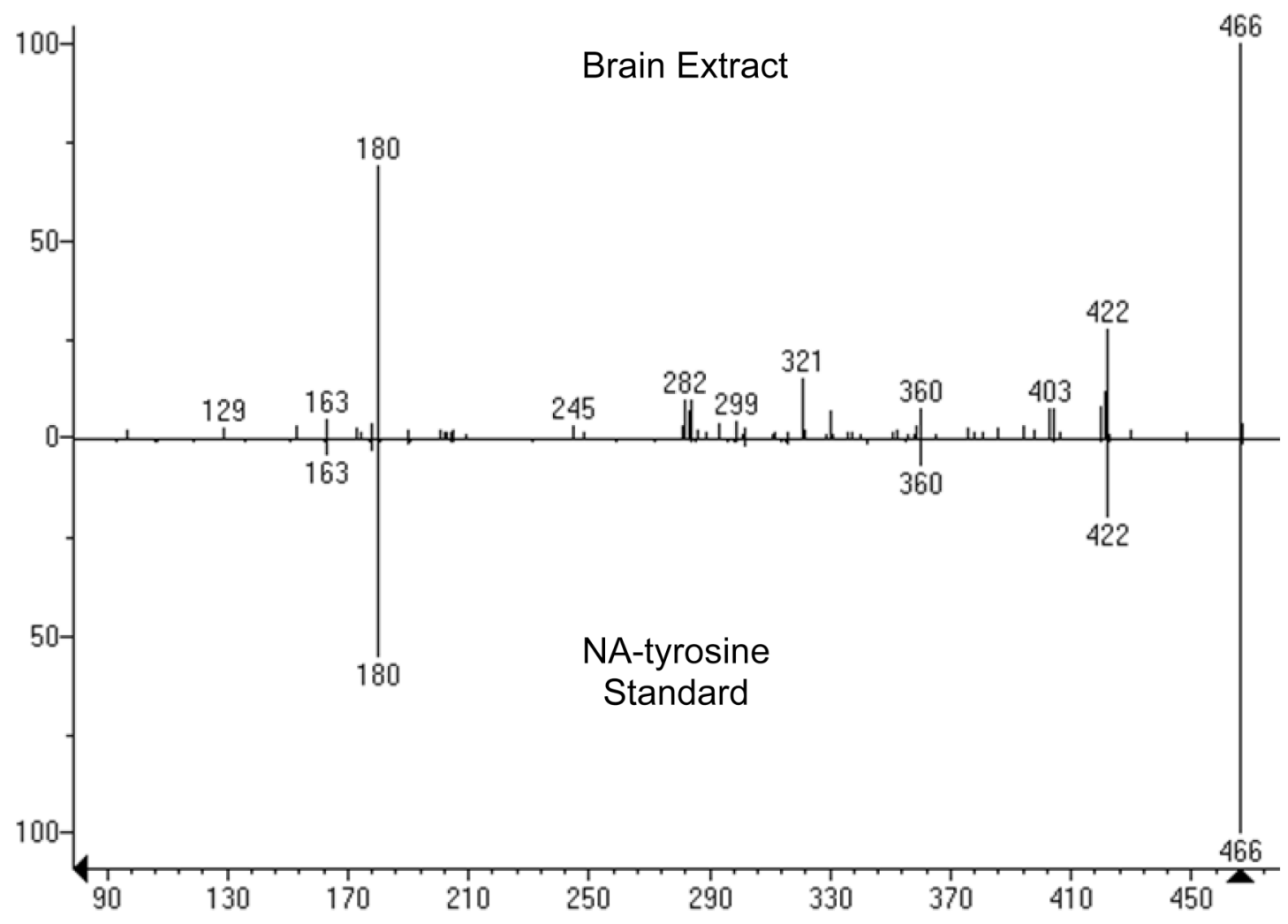


(C)
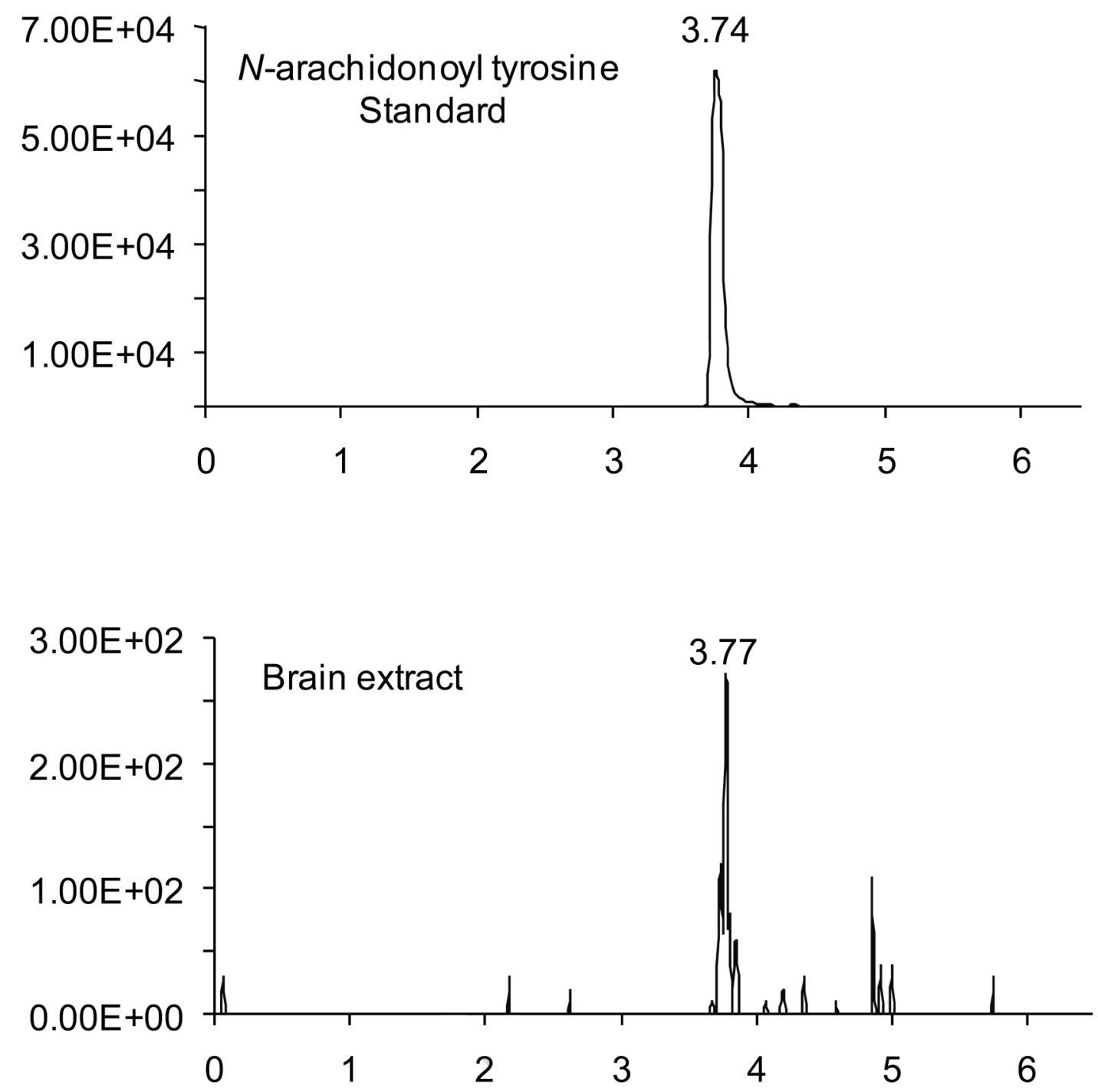

Figure 4.

Identification of NA-tyrosine in rat brain. (A) Chemical structure of NA-tyrosine. (B) The mass spectrum of the material in rat brain extract (top plot) and synthetic NA-tyrosine (bottom plot) via QqTOF LC/MS/MS were virtually identical. The prominent parent ion at $m / z, 446.3$ $[\mathrm{MH}]^{-}$of NA-tyrosine was observed for the material in the brain extract and synthetic NAtyrosine. (C) Multiple-reaction monitoring on a triple-quadrupole mass spectrometer revealed co-eluting peaks with molecular/fragment ions at $\mathrm{m} / \mathrm{z}$ 446.3/179.9 from synthetic NA-tyrosine and the material in rat brain extract. 


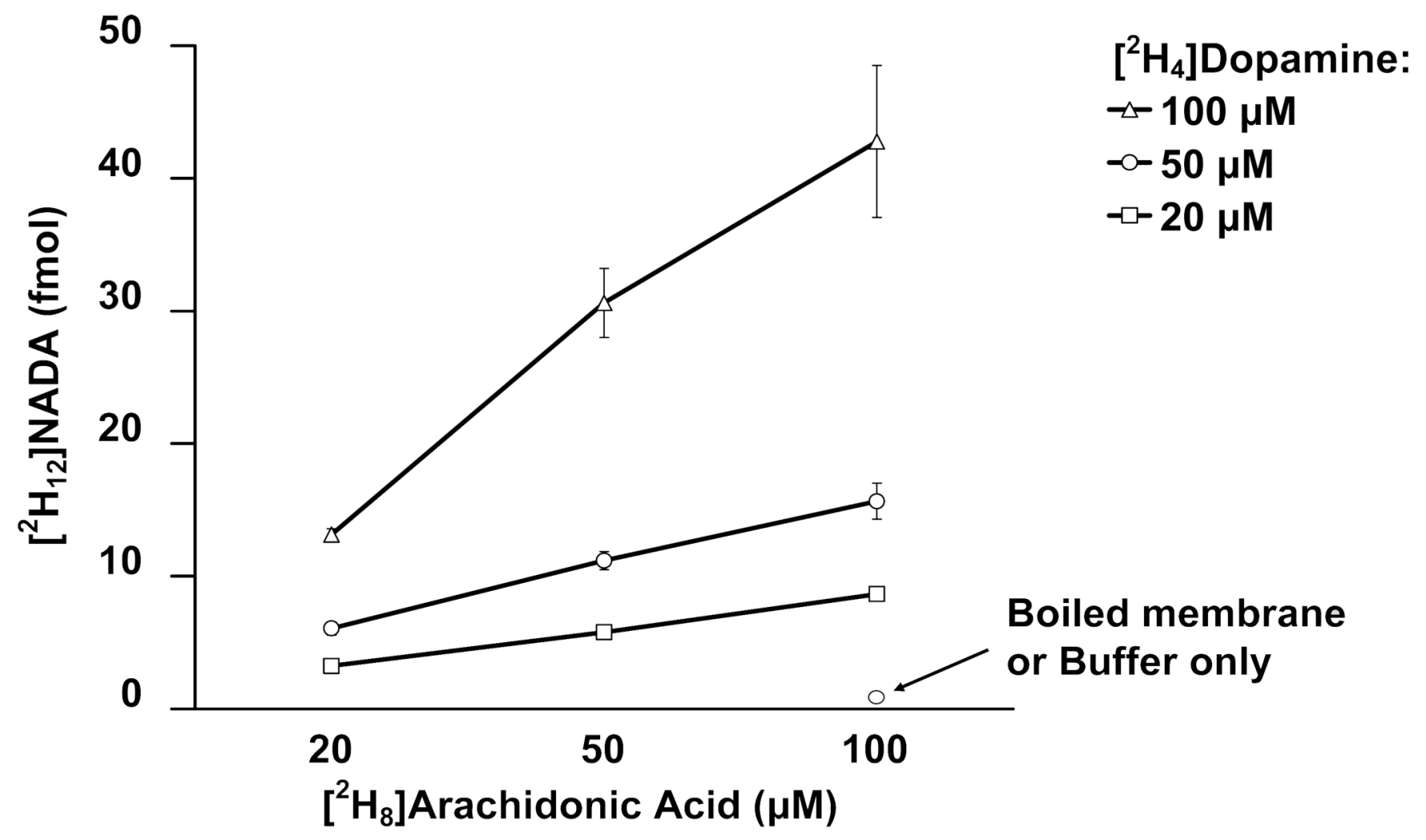

Figure 5.

Biosynthesis of $\left[{ }^{2} \mathrm{H}_{12}\right]$ NADA by incubation of $\left[{ }^{2} \mathrm{H}_{8}\right]$ arachidonic acid and $\left[{ }^{2} \mathrm{H}_{4}\right]$ dopamine with rat brain membrane homogenates. Rat brain membranes were incubated with 20,50, and 100 $\mu \mathrm{M}\left[{ }^{2} \mathrm{H}_{8}\right]$ arachidonic acid and 20,50, and $100 \mu \mathrm{M}\left[{ }^{2} \mathrm{H}_{4}\right]$ dopamine, respectively in Tris- $\mathrm{HCl}$ buffer at $37^{\circ} \mathrm{C}$ for $25 \mathrm{~min}\left(\mathrm{n}=9\right.$ for each condition). The production of $\left[{ }^{2} \mathrm{H}_{12}\right]$ NADA was concentration-dependent with higher concentrations of precursors leading to higher concentrations of product. Deuterated NADA was not detected when buffer or boiled membranes were incubated with the precursors or when membranes were incubated without the precursors. Values are means \pm SEM from 3 independent experiments performed in triplicate. 
(A)

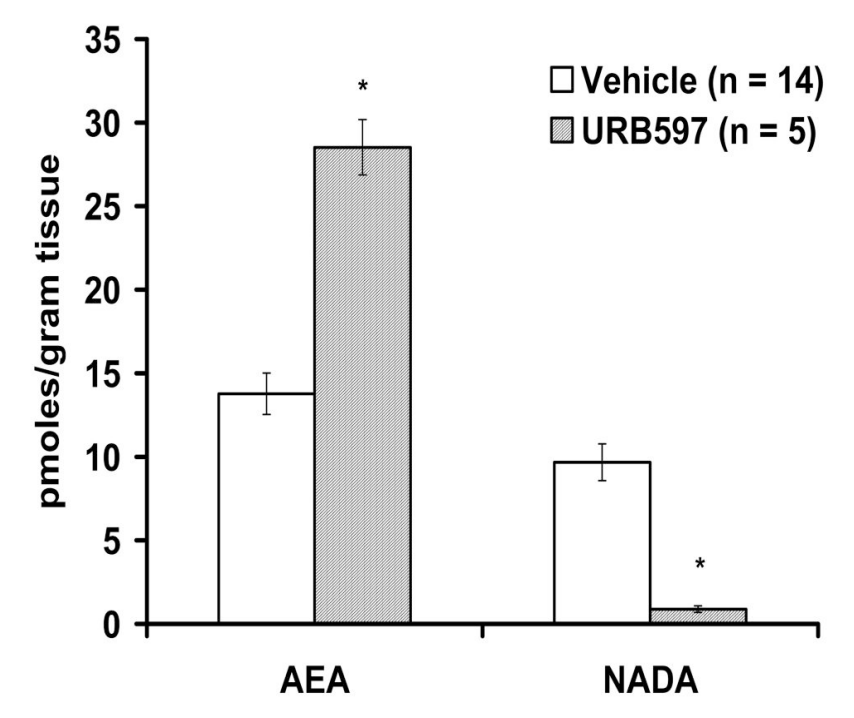

(B)

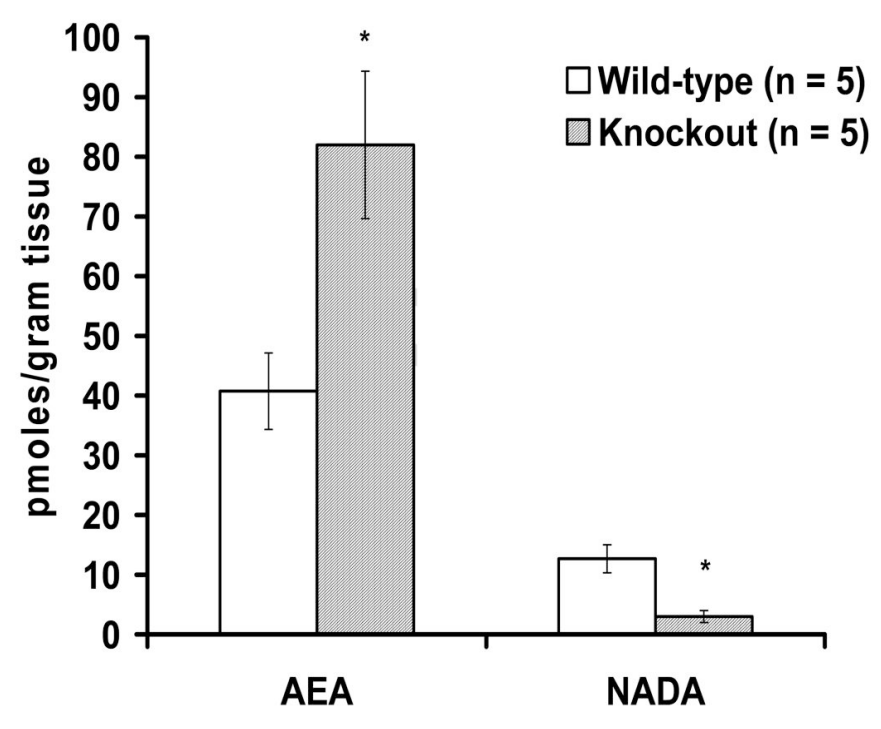

Figure 6.

Pharmacological and genetic inhibition of FAAH increases striatal AEA and decreases striatal NADA. (A) Levels of AEA and NADA in rat striata 2 hours after vehicle $(n=14)$ or $0.3 \mathrm{mg} /$ $\mathrm{kg}$ URB597 $(\mathrm{n}=5)(* p<0.05)$. (B) Levels of AEA and NADA in mouse striata of wild-type $(\mathrm{n}=5)$ or FAAH knockout $(\mathrm{n}=5)(* p<0.05)$. 
(A)

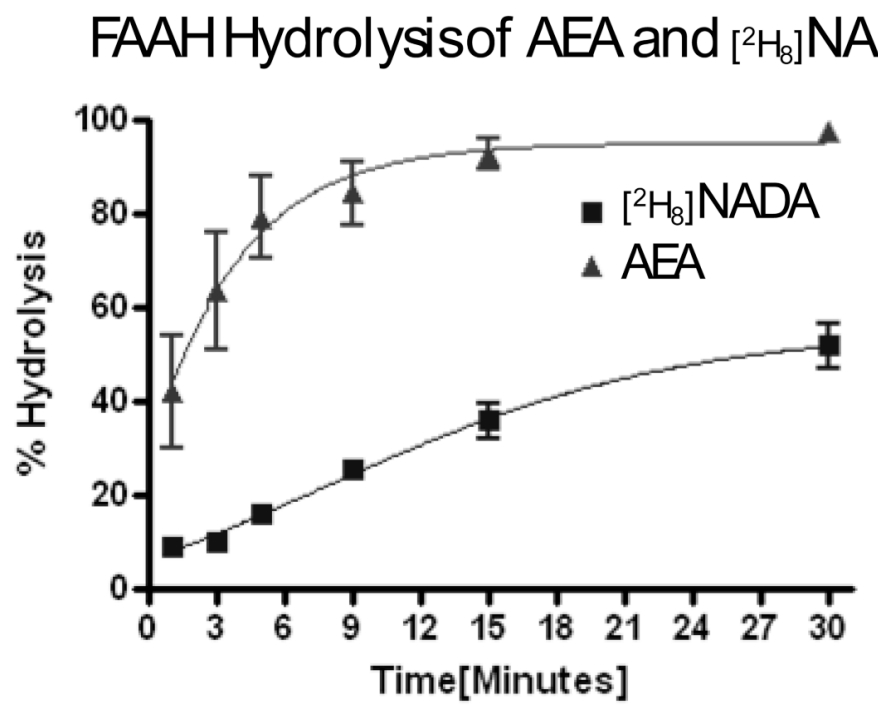

(B)

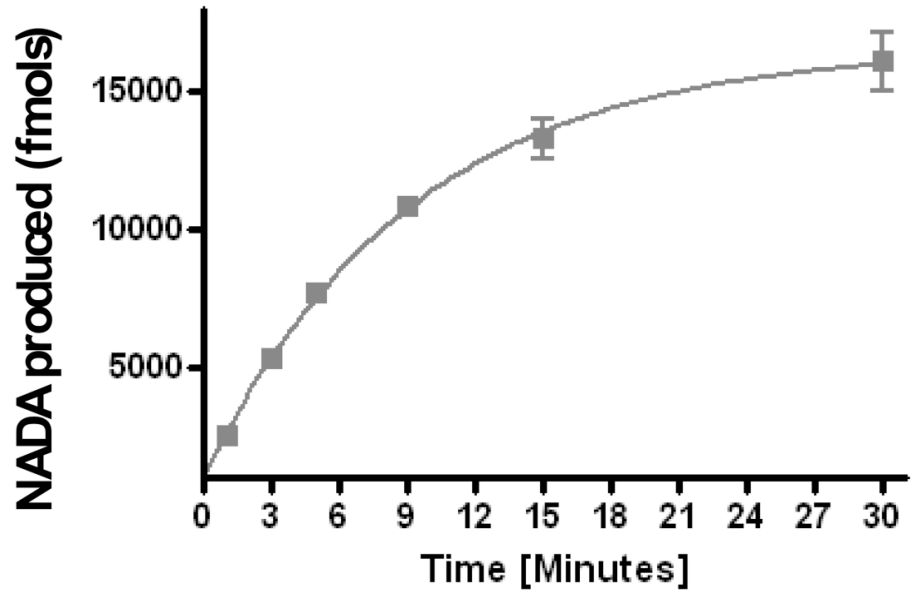

Figure 7.

Hydrolysis and biosynthesis of NADA via recombinant FAAH. A) Comparisons of hydrolysis rates of AEA and $\left[{ }^{2} \mathrm{H}_{8}\right]$-NADA. B) De novo production of NADA from incubations of AEA, dopamine and recombinant FAAH. 
Table 1

Mass Measurement of $\mathrm{MH}^{-}$and Product Ions from Rat Brain Extract and Structural Assignments Conducted with Qq-TOF LC/MS/MS

Putative $N$-Arachidonoyl tyrosine (NA-Tyrosine)

\begin{tabular}{lll}
\hline Common Fragments m/z (ppm) & Proposed Formulae & Proposed Fragmentation \\
\hline $466.3058(20.4)$ & $\mathrm{C}_{29} \mathrm{H}_{40} \mathrm{NO}_{4}^{-}$ & $\mathrm{MH}^{-}$ \\
$422.3223(37.5)$ & $\mathrm{C}_{28} \mathrm{H}_{40} \mathrm{NO}_{2}^{-}$ & $\mathrm{MH}^{-}-\mathrm{CO}_{2}$ \\
$331.2750(-39.4)$ & $\mathrm{C}_{22} \mathrm{H}_{37} \mathrm{NO}^{-}$ & $\mathrm{MH}^{-}-\mathrm{C}_{7} \mathrm{H}_{3} \mathrm{O}_{3}$ \\
$180.0703(20.5)$ & $\mathrm{C}_{9} \mathrm{H}_{10} \mathrm{NO}_{3}^{-}$ & $\mathrm{MH}^{-}-\mathrm{C}_{20} \mathrm{H}_{30} \mathrm{O}\left(20: 4-\mathrm{H}_{2} \mathrm{O}\right) ;$ or $[\mathrm{Tyr}-\mathrm{H}]^{-}$ \\
\end{tabular}

* Mass measurements and errors (ppm difference from theoretical exact mass) of at least 10 consecutive scan average. 